\title{
Silikazko nanopartikula mesoporotsuak biomedikuntzan
}

\author{
(Mesoporous Silica Nanoparticles in biomedicine)
}

Maider Ugalde-Arbizu*

Kimika Aplikatua, Donostiako Kimika Fakultatea (UPV/EHU), Donostia

LABURPENA: Silikazko nanopartikula mesoporotsuak (MSNak) aurreko mendetik ezagutzen diren arren, azkeneko hamarkadan arreta handia bereganatu dute. Material mota hauen propietateak (hala nola, poro-bolumen zein gainazaleko eremu handiak) biomedikuntzaren arloan ikertzeko bereziki aproposak izatea eragin du. Gainera, propietate horiek moldakorrak dira, eta horrek, gaur egungo biosistemen aldean abantaila handiko konposatuak izatea eragiten du. Bestalde, MSNak optikoki gardenak, kimikoki geldoak, mekanikoki egonkorrak eta nahiko biobateragarriak dira. Hori dela eta, artikulu honek nanopartikula hauen propietateak azaltzea eta biomedikuntzaren arloan zentratzea du helburutzat. Azken arlo honetan, gaur egun arteko aplikaziorik aztertuenak azalduko dira; alde batetik, agente terapeutikoen garraioa, eta bestetik, bioirudiak.

HITZ GAKOAK: silikazko nanopartikula mesoporotsuak, MSN, agente terapeutikoen garraioa, bioirudiak.

ABSTRACT: Although mesoporous silica nanoparticles (MSNs) have been known for the last century, they have attracted considerable attention during the last decade motivated by their outstanding properties. In fact, these materials possess large surfaces and pore volumes, which make them especially suitable for research in biomedicine. In addition, the aforementioned properties can be modulated which makes these compounds of great advantage over current biosystems. Furthermore, MSNs are optically transparent, chemically inert, mechanically stable, and quite biocompatible. Therefore, the aim of this article is to delve into the properties of these nanoparticles focusing on the field of biomedicine. Moreover, the most studied applications on drug delivery and bioimaging will be analysed.

KEYWORDS: mesoporous silica nanoparticles, MSN, drug delivery, bioimaging .

\footnotetext{
* Harremanetan jartzeko / Corresponding author: Maider Ugalde-Arbizu. Kimika Ez-Organikoa, Kimika Aplikatuaren Saila, Kimika Fakultatea, Manuel Lardizabal Pasealekua, 3 (20018 Donostia). - maider.ugalde@ehu.eus - https://orcid.org/00000001-7732-5637.

Nola aipatu / How to cite: Ugalde-Arbizu, Maider (2021). "Silikazko nanopartikula mesoporotsuak biomedikuntzan»; Ekaia, 39, 2021, 113-129. (https://doi.org/10.1387/ekaia.21783).

Jasoa: 2020, ekainak 2; Onartua: 2020, irailak 9.

ISSN 0214-9001 - eISSN 2444-3255 / (c) 2021 UPV/EHU
}

(c) (i) (1) Obra hau Creative Commons Atribución 4.0 Internacional-en lizentziapean dago 


\section{SARRERA}

Silikazko nanopartikulak silizio dioxidoz $\left(\mathrm{SiO}_{2}\right)$ osatutako partikulak dira. Partikula hauek siloxano-loturen bidez ( $\mathrm{Si}-\mathrm{O}-\mathrm{Si}$ ) osatutako $\mathrm{SiO}_{4}$ unitate tetraedrikoen sare ez-organiko bat dute ezaugarritzat, zeinetan silanoltaldeak (Si-OH) partikularen gainazalean dauden. Esan bezala, beraz, nanopartikula hauek silizioz eta oxigenoz osatuta daude [1]. Silizioa lurrazaleko bigarren elementurik ugariena da, oxigenoaren ondoren. Lurrazalaren $\% 28$ kuartzoz osatuta dago, eta azaleraren \% 49, berriz, silikatozko egitura duten beste mineral batzuez. Gainera, silizioa, giza gorputzeko hirugarren oligoelementurik ugariena ere bada, eta haren eskasiak zenbait nahasmendu sortzen ditu: hala nola, ilea hauskorra edo sistema muskulueskeletikoaren hantura sor ditzake $[2,3]$.

Bestalde, nanopartikuletara itzuliz, silikazko nanopartikula mota ezberdinak daude: hala nola, pororik gabeak, mesoporotsuak (alegia 2-50 nm bitarteko poroak dituzten nanopartikulak), nanopartikula hutsak (hollow nanoparticles), hagatxo formakoak eta nanopartikula dendritikoak [4].
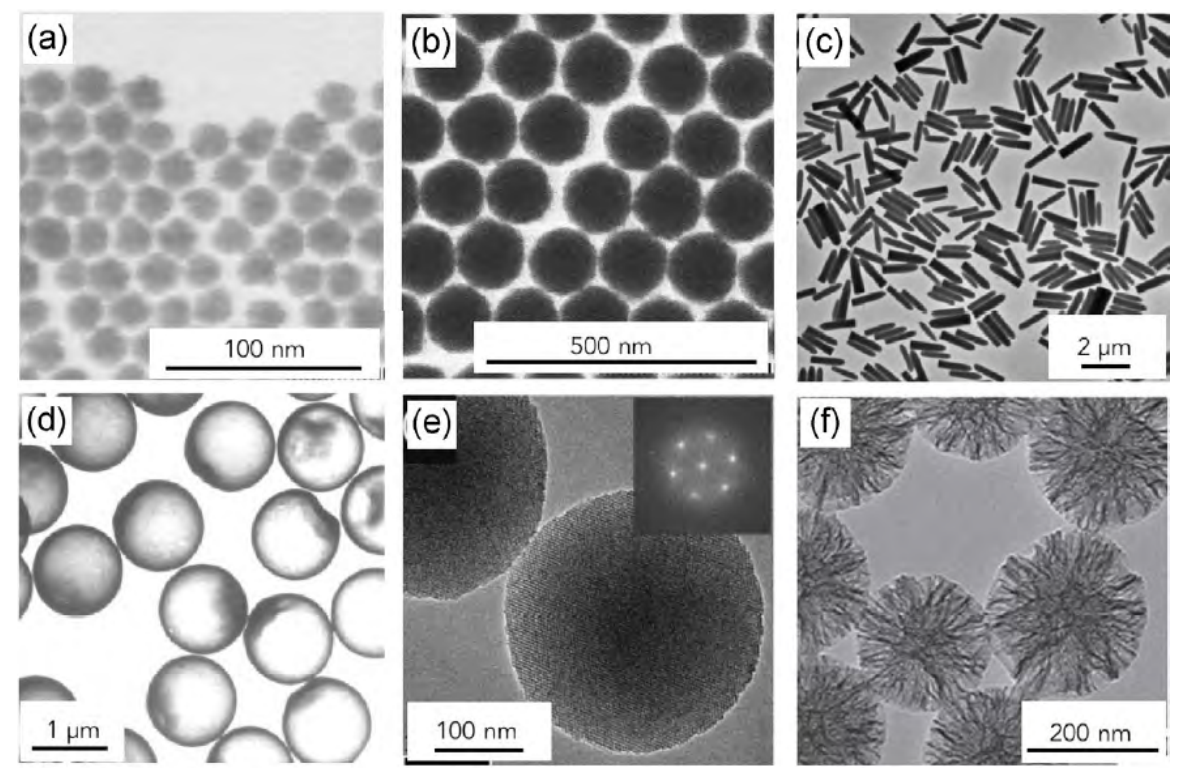

1. irudia. TEM motako mikroskopia bidez ateratako silikazko nanopartikulen zenbait irudi: (a,b) pororik gabeko nanopartikulak, 19 eta $120 \mathrm{~nm}$-ko tamainadunak, hurrenez hurren, (c) hagatxo formako nanopartikulak, (d) nanopartikula hutsak, (e) nanopartikula mesoporotsuak eta (f) nanopartikula dendritikoak [4]. 
Oro har silikazko nanopartikulak erabilera anitzeko konposatuak diren arren, arlorik ikertuena biomedikuntzarena da. Izan ere, biomedikuntzaaplikazioetarako beharrezkoa da sistemen biobateragarritasuna eta toxizitate eza. Ildo horretan, silikazko materialak egokiak dira, optikoki gardenak, kimikoki geldoak, mekanikoki egonkorrak eta nahiko biobateragarriak direlako. Gainera, haien gainazala funtzionaliza daiteke propietate horiek moldatuz [5]. Biomedikuntzaren arlo honetan, nanopartikula ikertuenak mesoporotsuak dira [6]. Hori dela eta, lan honek nanopartikula horien propietateak azaltzea eta biomedikuntzaren arloan izan dezaketen zenbait aplikazio aurkeztea du helburutzat.

\section{SILIKAZKO NANOPARTIKULA MESOPOROTSUAK}

Silikazko nanopartikula mesoporotsuak MSN (Mesoporous Silica Nanoparticles) laburduraren bidez ezagutzen dira. Nanopartikula hauek 1990eko hamarkadan sintetizatu ziren lehen aldiz. Material familia honen ezaugarri orokorrak honako hauek dira $[7,8]$ :

- 2 eta $50 \mathrm{~nm}$ arteko tamaina homogeneoa duten poroen banaketa ordenatua dute.

- Poro-bolumen handia dute (gutxi gorabehera $1 \mathrm{~cm}^{3} \mathrm{~g}^{-1}$ ).

- Gainazalaren eremu handia (gutxi gorabehera $1.000 \mathrm{~m}^{2} \mathrm{~g}^{-1}$ ).

- Silanol multzoen $(\mathrm{Si}-\mathrm{OH})$ dentsitate handia azaleran; honek ondorengo funtzionalizazio-prozesuak erraztu ditzake; izan ere, $\mathrm{OH}$ taldea beste molekula askorekin erreakzionaraz daiteke.

Partikulen poro horiei esker, material hauek zenbait aplikazio izan ditzakete zenbait arlotan, besteak beste katalisian eta biomedikuntzan. Poroaren eta partikularen tamaina zein forma garrantzitsuak dira partikulei erabilgarritasuna eman nahi zaienean: adibidez, poroetan farmakoak adsorbatu nahi direnean, besteak beste, nanopartikulak tamaina egokiko poroak izan behar ditu farmakoa han sar dadin. Horretarako, hainbat nanopartikula mota daude: azpiko taulan (1. taula) azaltzen dira horietako batzuk [8]. 
1. taula. Silikazko nanopartikula mesoporotsuen (MSN) adibide batzuk [8].

\begin{tabular}{c|l|l|c|c}
\hline $\begin{array}{c}\text { MSN } \\
\text { familia }\end{array}$ & $\begin{array}{c}\text { MSN } \\
\text { mota }\end{array}$ & \multicolumn{1}{|c|}{ Poroaren simetria } & $\begin{array}{c}\text { Poroaren } \\
\text { tamaina } \\
(\mathrm{nm})\end{array}$ & $\begin{array}{c}\text { Poroaren } \\
\text { bolumena } \\
\left(\mathrm{cm}^{3} / \mathrm{g}\right)\end{array}$ \\
\hline KIT & KIT-5 & Kubikoa Fm3m & 9.3 & 0.45 \\
\hline COK & COK-12 & Hexagonala P6m & 5.8 & 0.45 \\
\hline \multirow{3}{*}{ M41S } & MCM-41 & 2D hexagonala $P 6 m m$ & $1.5-8$ & \\
& MCM-48 & 3D kubikoa I $a 3 d$ & $2-5$ & $>1.0$ \\
& MCM-50 & Laminarra $p 2$ & $2-5$ & 0.68 \\
& SBA-11 & 3D kubikoa $P m 3 m$ & $2.1-3.6$ & 0.83 \\
SBA & SBA-12 & 3D hexagonala $P 6_{3} / m m c$ & 3.1 & 1.17 \\
& SBA-15 & 2D hexagonala $p 6 m m$ & $6-10$ & 0.91 \\
\hline
\end{tabular}

KIT-Korea Advanced Institute of Science and Technology; COK-Centre for Research Chemistry and Catalysis; MCM-Mobil Crystalline Materials; SBA-Santa Barbara Amorphous.

\subsection{MSNen sintesia}

Lehenik eta behin, MSNak sintetizatzeko eta haien diametroa eta poroen tamaina kontrolatzeko, Werner Stöber-en sintesian oinarritutako erreakzioak erabili ohi dira. Stöber-ek, bere ikerketa-taldearekin batera, 1968an silikazko $\left(\mathrm{SiO}_{2}\right)$ partikulak tamaina bertsuekin sintetizatzeko modua argitaratu zuen [9]. Sintesi honen bidez, 0,05-2 $\mu \mathrm{m}$ bitarteko partikulak sintetiza daitezke. Horretarako, tetraetil ortosilikatoa (TEOS) edo beste silikato bat uraren, alkoholaren eta amoniakoaren nahastearekin elkartu eta irabiatu egiten da. Partikula hauen tamaina disolbatzailearen eta silika-iturrien kontzentrazioen araberakoa izango da [10,11].

Beraz, esan bezala, Stöber-en erreakzioa oinarritzat hartuta eta zenbait moldaketa eginez, silikazko nanopartikula mesoporotsuak sintetizatu dira. Sintetizatu zen lehen MSNa MCM-41 (Mobil Composition of Matter No. 41) izenez ezagutzen da. Horretarako, tetraetil ortosilikatoa (TEOS) silika-iturri gisa erabiltzen da, eta zetiltrimetilamonio bromuroa (CTAB) tentsoaktiboa, berriz, plantilla moduan. Erreakzioa uretan eta baldintza basikoetan egiten da [12]. Honako irudi honetan, MCM-41 erreakzioaren laburpen bat ikus daiteke: 


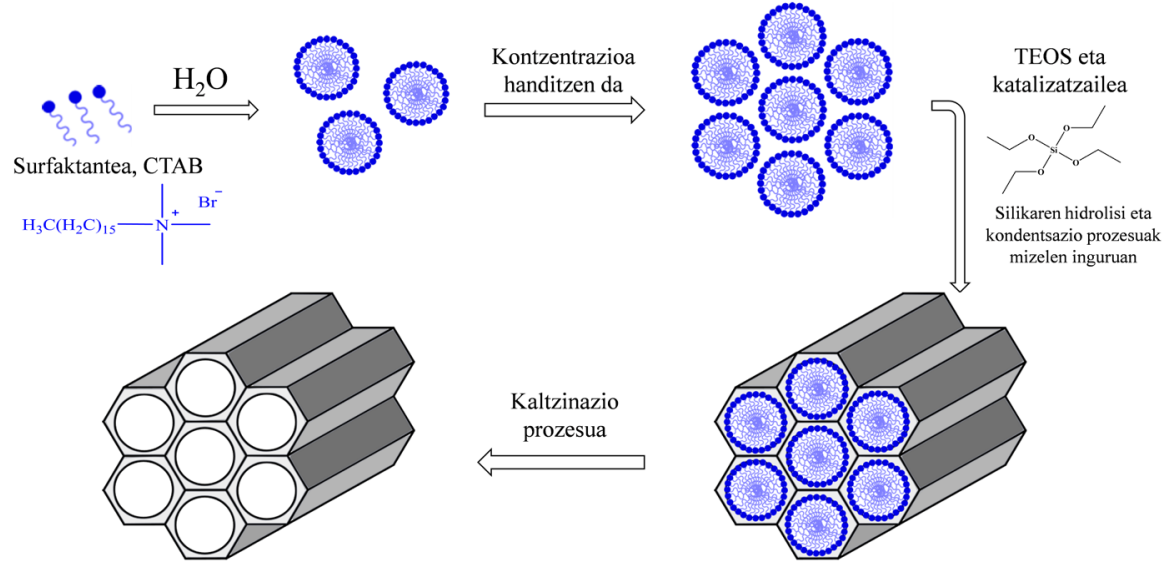

2. irudia. MCM-41 motako nanopartikulen sintesiaren irudikapena.

Beraz, CTAB surfaktantea uretan disolbatzen da, eta mizelak osatzen hasten dira. Mizelen kontzentrazioa handitzean, hauek era hexagonalean elkartzen dira. TEOSa eta sodio hidroxidoa (katalizatzaile gisa erabiltzen da) gehitzean, mizelen inguruan silizioaren kondentsazioa eta hidrolisi-prozesuak gertatzen dira, eta horrela, egitura osatzen da. Azkenik, tentsoaktiboak guztiz kanporatzeko kaltzinazio-prozesua egin ohi da [8].

\subsection{MSNen propietateak}

Silikazko nanopartikula mesoporotsuek ondoren aztertuko diren propietatea fisiko-kimiko moldagarriak dituzte: hala nola, partikulen eta poroen tamaina. Nanopartikulen moldakortasun honek, medikamentuen garraioaren (drug delivery terminoaz ezagutzen dena) arloan MSNen erabilera sustatu du, poroetan mota askotariko biomolekulak eta agente terapeutikoak sartu zein irten daitezkeelako [7].

\subsubsection{Partikularen tamaina}

Partikulen diametroa baldintza sintetikoen arabera molda daiteke, mikrometro gutxi batzuetatik nanometro gutxi batzuetara. Baldintza sintetikoen artean, $\mathrm{pH}$-a funtsezkoa da; izan ere, partikularen tamaina modu eraginkorrean kontrola daiteke agente gehigarri egokiak gehituz, hala nola alkoholak, aminak, base ez-organikoak edo gatz ez-organikoak. Agente horiek silizearen hidrolisian eta kondentsazio-prozesuan eragin eta erreakzio-zinetika bizkortzen dute, eta horrela tamaina txikiagoko partikulak eratu. [13]. Ondorioz, medikamentuen garraiorako edo beste edozein aplikaziotarako egokiak diren tamainako partikulak sintetiza eta optimiza daitezke [7]. 


\subsubsection{Poroen tamaina}

Partikulen poroen tamaina faktore garrantzitsua da; izan ere, partikularen barruan zer molekula sar daitekeen mugatzen du. Poroen tamaina $2 \mathrm{~nm}-$ tik $30 \mathrm{~nm}$-tara alda daiteke, erabiltzen den surfaktantearen eta sintesi-baldintzen arabera. Hala nola, SBA-15 motako partikulek 6-10 nm bitarteko poroak dituzte, baina sintesian 1,3,5-trimetilbenzenoa gehituz gero, poroak $30 \mathrm{~nm}$ arte handitu daitezke [14]. Bestalde, tamaina handiko poroak dituzten partikulak proteinak, entzimak, antigorputzak eta azido nukleikoak adsorbitzeko eta hornitzeko erabiltzen dira [7, 13].

\subsubsection{Poroen bolumena}

Poroen bolumena faktore garrantzitsua da haietan molekulak sartu nahi direnean. Zenbat eta poro-bolumen handiagoa, orduan eta molekula gehiago kargatuko dira partikulan. Ohiko MSNen poro bolumena $1 \mathrm{~cm}^{3} / \mathrm{g}$ inguruan dabil $[7,13]$. Hala eta guztiz ere, C. L. Haynes-en taldeak poroen bolumena $4,5 \mathrm{~cm}^{3} / \mathrm{g}$ arte handitzea lortu du gainazal handia mantenduz $\left(>1.000 \mathrm{~m}^{2} / \mathrm{g}\right)$ [15]. Bestalde, MSNen poroen egitura kontrolatzeak hainbat tamainatako molekulak modu selektiboan kargatzeko aukera ematen du $[7,13]$.

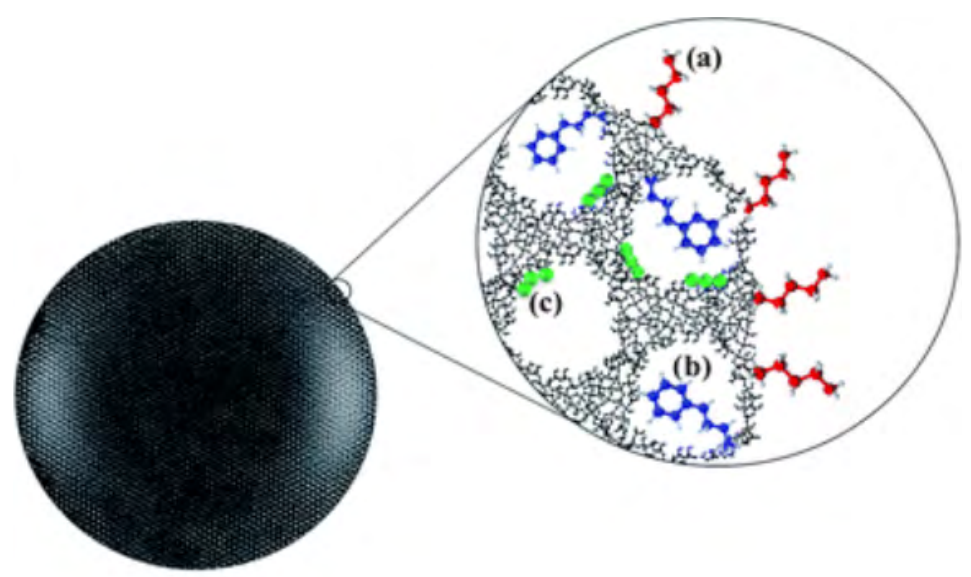

3. irudia. Talde funtzionalen sarrera nanopartikularen eskualde jakinetan: (a) kanpoko gainazalean, (b) poroaren sarreran eta (c) paretetan [13]. 


\subsubsection{Gainazalaren funtzionalizazioa}

Nanopartikula hauen propietate abantailatsuenetako bat da partikularen eskualde jakinetan hainbat talde funtzional ezberdinekin funtzionalizatzeko erraztasuna. Nanopartikularen funtzionalizazio horrek MSNak moldakorrak izatea eragiten du; izan ere, gainazalak funtzionalizatzeari esker, farmakoak, proteinak... adsorbitu edo lotura kobalenteak osa daitezke. Gainazalaren funtzionalizazio hori hiru tokitan egin daiteke ikus (ikus 3. irudia): poroen paretetan, partikularen barruko zein kanpoko gainazalean eta poroen sarreran [13].

\section{MSN-en APLIKAZIOAK BIOMEDIKUNTZAN}

Aurretik aipatu den bezala, silikazko nanopartikulak egokiak izan daitezke biomedikuntzarako. Gainera, MSNak sistema egonkorragoak dira hainbat ingurune biologikotan polimeroak bezalako beste biomaterial askorekin alderatuta. Dena den, MSNekin in vivo eta in vitro azterketa asko egin diren arren, animaliaren ehunak erabiltzen dituzten batzuk barne, oraindik ez da proba klinikorik egin gizakiengan. Probak egin ez diren arren, nanopartikula hauek biomedikuntzaren arloan zenbait aplikazio izan ditzakete: besteak beste, hurrengo ataletan aztertuko direnak [16].

\subsection{Agente terapeutikoen garraioa (drug delivery)}

2001ean Vallet-Regí-k MSNen erabilera medikamentuen garraioan aztertzen zuen lehen artikulua argitaratu zuen. Han, ibuprofenoa (aski ezaguna den antiinflamatorio bat) MCM-41 motako nanopartikulen poroetan sartu zuten, farmakoak kargatzeko gaitasun handia eta haien askapen kontrolatua erakusteko asmoz [17]. Orduz geroztik, alor honetan gehiago ikertu da eta honela frogatu da MSNek eragile terapeutiko ugari kargatzeko abantailak dituztela: besteak beste, farmakoak, proteinak eta geneak [18].

Gainera, MSNak farmakoak garraiatzeko ohiko sistemak (polimeroen nanopartikulak, liposomak, eta abar) baino malguagoak, sendoagoak eta moldakorragoak dira. Ohiko nanoportadore organikoen mugak hauek dira: etekin baxua, produkzio-koste altua, farmakoaren distribuzio heterogenoa matrizean zehar eta farmakoaren karga-ahalmen eskasa. Aitzitik, MSNek ez dituzte muga horiek. Alde batetik, eskala handian ekoizteko abantaila dute polimeroen nanopartikulen eta liposomen aldean; prozesu hori nahiko erraza eta koste baxukoa da. Bestetik, MSN mota ezberdinak daudenez batzuk ahalmen handia dute molekulak kargatzeko, eta molekula horien askatze-prozesua baldintza fisiologikoetan egin daiteke [18]. 
Farmakoak nanopartikuletan kargatzeko prozesua bi modutan egin daiteke; batetik, nanopartikulen sintesian bertan, eta bestetik, nanopartikulak sintetizatu ostean kimisortzio edo fisisortzio prozesuen bidez. Azken kasu honetan, kargatze-prozesuaren optimizazioa errazago egiten da [7]. Bestalde, farmakoaren askatze-prozesua ere bi modutan egin daiteke. Lehenengo modua matrizean zeharreko difusioaren bitartez da (normalean, lehen mailako zinetika jarraitzen du). Bigarrena, berriz, estimulu bati erantzunez gertatzen da askatze-prozesua. Estimulu hori izan daiteke kanpokoa (hala nola, argi ultramorea) zein barrukoa (adibidez, gorputzeko $\mathrm{pH}$ aldaketak, aktibitatea entzimatikoak, erredox potentzialak...). Bigarren kasuari dagokionez, interes handiagoko prozesua da; izan ere, honela farmakoa nahi dugun gorputz-atalera bideratu daiteke, askatze-prozesua selektiboagoa eginez [19].

Ondoren, estimuluen bidezko farmakoaren askatze-prozesua hobeto ulertzeko asmoz, bi adibide aztertuko dira. Lehenengoan, kanpoko estimuluen bidez gertatzen da. Y. Zhao-k Angewandte Chemie aldizkarian 2012. urtean argitaratutako artikuluan, bihotz-hutsegiteak saihesteko kurkumina izeneko molekula garraiatuko duen nanopartikulak sintetizatu zituen, kurkuminaren askatze-prozesua fototermikoki kontrolatuz. Kurkumina, kurkuma landaretik eratorria den koloratzaile naturala da, agente terapeutikoa, eta, besteak beste, propietate antioxidatzaile eta antiinflamatorioak dauzka [20].

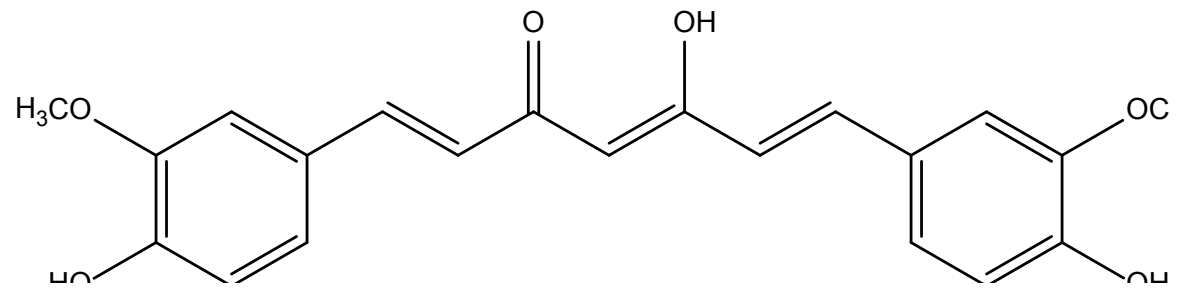

4. irudia. Kurkumina agente terapeutikoaren egitura kimikoa.

Kurkumina garraiatuko zuen nanopartikula sintesia hasteko, argiarekiko sentsiblea den molekula bat (photoswitch terminoaren bidez ezagutzen diren molekula mota) sintetizatu zuten. Horretarako, azobentzenoaren deribatu bat erabili zuten, izan ere, azobentzenoa isomerizatu egiten da argi ultramore-ikusgaiaren bidez. Honela, azobentzenoa trans isomerotik cis isomerora pasa daiteke. Alderantzizko isomerizazioa, alegia cis-etik transera pasatzea, ilunpetan gertatzen da, eta berezkoa trans isomeroa da termodinamikoki egonkorrena baita $[20,21]$. 


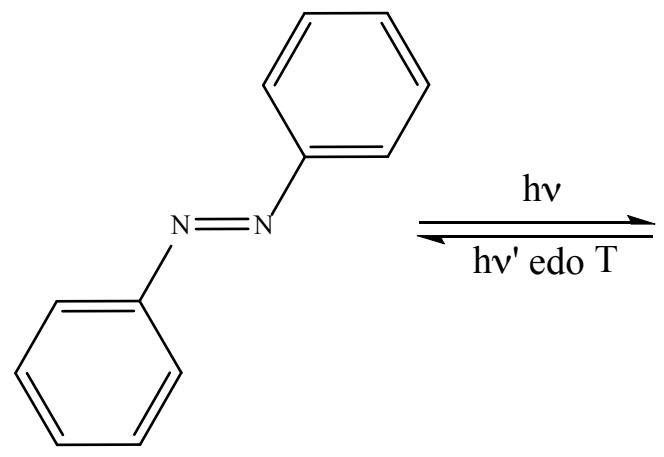

trans-azobentzenoa

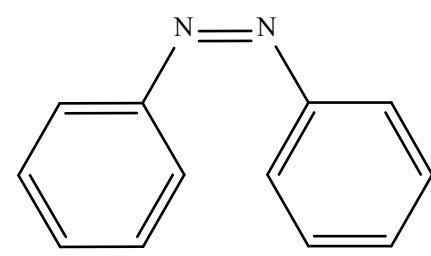

cis-azobentzenoa

5. irudia. Azobentzenoaren isomerizazioaren irudikapena.

Jarraitzeko, MSNak $\alpha$-ziklodestrin ( $\alpha$-CD) eraztunarekin (6 glukosaz osatutako eraztuna) funtzionalizatu zituzten. Eraztun hori fototermikoki sentikorra den azobentzenoaren ardatz lineal batekin lotu zuten. Azobentzeno horrek mutur batean tapoi bat zuen, bi talde sulfonikoz osatua (ikus 6. irudia) [20].
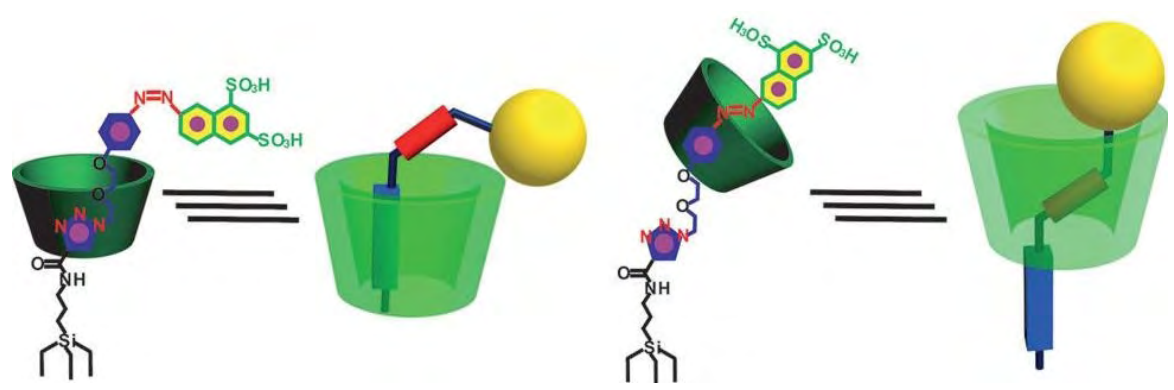

6. irudia. MSN funtzionalizatua erakusten duen eskema. Urdina: nanopartikulari lotuta dagoen zatia. Berdea: $\alpha-C D$ eraztuna. Gorria: fototermikoki sentikorra den azobentzenoaren $\mathrm{N}=\mathrm{N}$ lotura. Horia: bi talde sulfonikoz osatuta dagoen tapoia [20].

$\alpha-C D$ eraztunaren posizioa, azobentzenoaren isomerizazioa dela eta, lekuz aldatzen zen. Azobentzenoa cis posizioan zegoenean, $\alpha-C D$ eraztuna triazol/ etilen glikolan posizioan zegoen, eta horrela, nanopartikulen poroak fisikoki blokeatuta zeuden ( $c i s-M S N)$. Ondorioz, poroetan zegoen kurkuminak ez zeukan ateratzeko aukerarik. cis-MSN argi ikusgarriaren edo berotzearen eraginpean jartzean, azobentzenoaren fotoiso- 
merizazioa gertatzen zen, eta hori dela eta, $\alpha$-CD eraztuna trans-azobentzenoa posizioan jartzen zen (hau da, nanopartikulen azaleratik urrun) eta poroak desblokeatu egiten ziren. Beraz, $\alpha-\mathrm{CD}$ eraztunaren joan-etorriko mugimenduek nanoporoak ixtea eta irekitzea eragiten zuen, eta horrela farmakoa biltegiratzea eta askatze-prozesu kontrolatua ahalbidetu (7. irudia) [20].

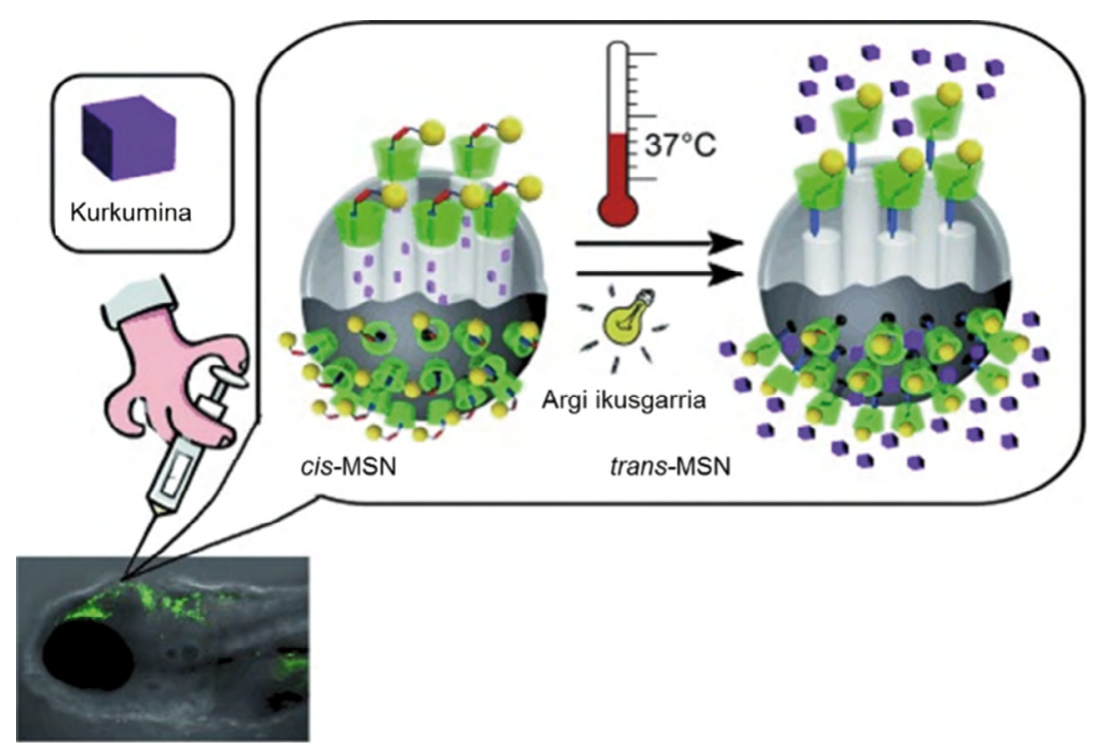

7. irudia. Zebra-arrainen larbetan farmakoekin kargatutako MSN injekzioaren irudikapen grafikoa. [20] (egileak moldatua).

Bukatzeko, zebra-arrainetan injektatu zuten, eta argiaren eta beroaren eragina in vivo aztertu zuten. Alde batetik, farmakoaren askatze-prozesua tenperaturaren bitartez egitea eraginkorragoa zela ondorioztatu zuten, eta bestetik, bihotz-hutsegiteen aurkako sistema egokia zela egiaztatu zuten [20].

Bigarren adibide honetan, askatze-prozesua barruko estimulu baten bidez gertatzen da, hain zuzen, aktibititate entzimatikoaren bidez. Y-J. Cheng-ek ACS Appl. Mater. Interfaces aldizkarian 2015. urtean argitaratutako artikuluan, Doxorrubizina (DOX) izenez ezagutzen den minbiziaren aurkako farmakoa garraiatzeko nanopartikulak sintetizatzea dute helburutzat [22].

Horretarako, aurreko adibidean bezala, farmakoa poroetan sartzen dute, eta ondoren, hainbat molekularen bidez poroak blokeatzen dituzte. 
Molekula horiek bitan sailkatu daitezke; batetik $\alpha$-CD erabiltzen dute poroen tapoi gisa, eta bestetik, 3 sekuentziaz osatutako oligopeptido bat gehitzen zaie nanopartikulei. Horietako sekuentzia batek nanopartikulak minbizidun zeluletara bideratzen laguntzen du; beste batek, berriz, materiala zelularen pareta zeharkatzen. Azkenik, nanopartikulak barruan daudenean, 3. sekuentzia katepsina B entzimaren aurrean apurtzen da, eta ondorioz, poroaren sarbideak desblokeatu eta farmakoa askatzen da (ikus 8. irudia) [22].

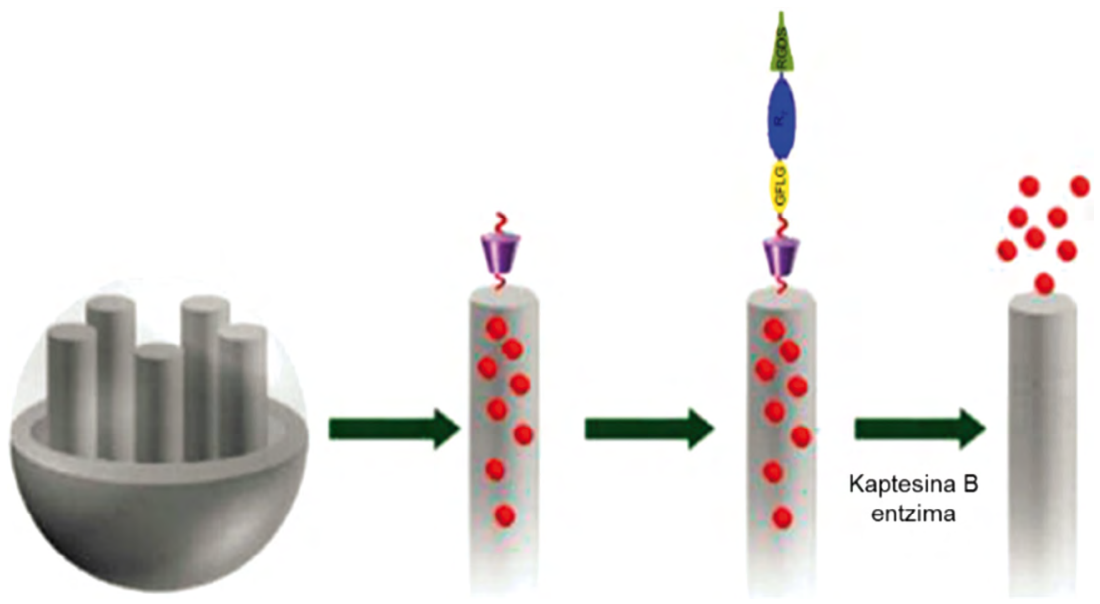

8. irudia. farmakoaren askatze-prozesua aktibitate entzimatikoaren bidez [20]. Morea: $\alpha-C D$ eraztuna. Gorria: DOX farmakoa. Horia, urdina eta berdea: oligopeptidoaren sekuentziak. (Egilea moldatuta.)

\subsection{Irudi biomedikoak, bioirudiak (bioimaging)}

Nanomedikuntzaren helburu nagusiak gaixotasunen diagnostiko goiztiarrak zein tratamendu eraginkorrak dira. Ildo honetan, bioirudiaren teknika ez-inbaditzaileak eta hainbat gaixotasun diagnostikatzeko tresnak azkar hobetu dira nanomaterialen garapenekin. Oro har, kalitate handiko irudi-agenteak ahalbidetzeko, honako baldintza hauek bete behar dira [23]:

- Egonkortasun kimikoa izan behar du hainbat baldintza fisiologiko$\tan$ (pH-a edo tenperatura).

- Soluzio koloidala mantendu behar du in vitro zein in vivo kasuetan.

- Irudi-kontraste ona izan behar du.

- Denbora luzez egon behar du odol-zirkulazioan zainen bitartez sartu ostean. 
MSNek dituzten ezaugarriak direla eta, irudi-agentea MSNan jarriz gero, lehen aipatutako baldintzak betetzeko etorkizun handiko sistema izan daiteke. Testuinguru horretan, MSNekin bateragarriak diren hainbat irudiagente mota garatu dira (ikus 9. irudia): hala nola, irudi optikoak, erresonantzia magnetikoaren bidezko irudiak (MRI), positroi-igorpenezko tomografia (PET), ordenagailu bidezko tomografia (CT) eta ultrasoinu bidezko irudiak [23].

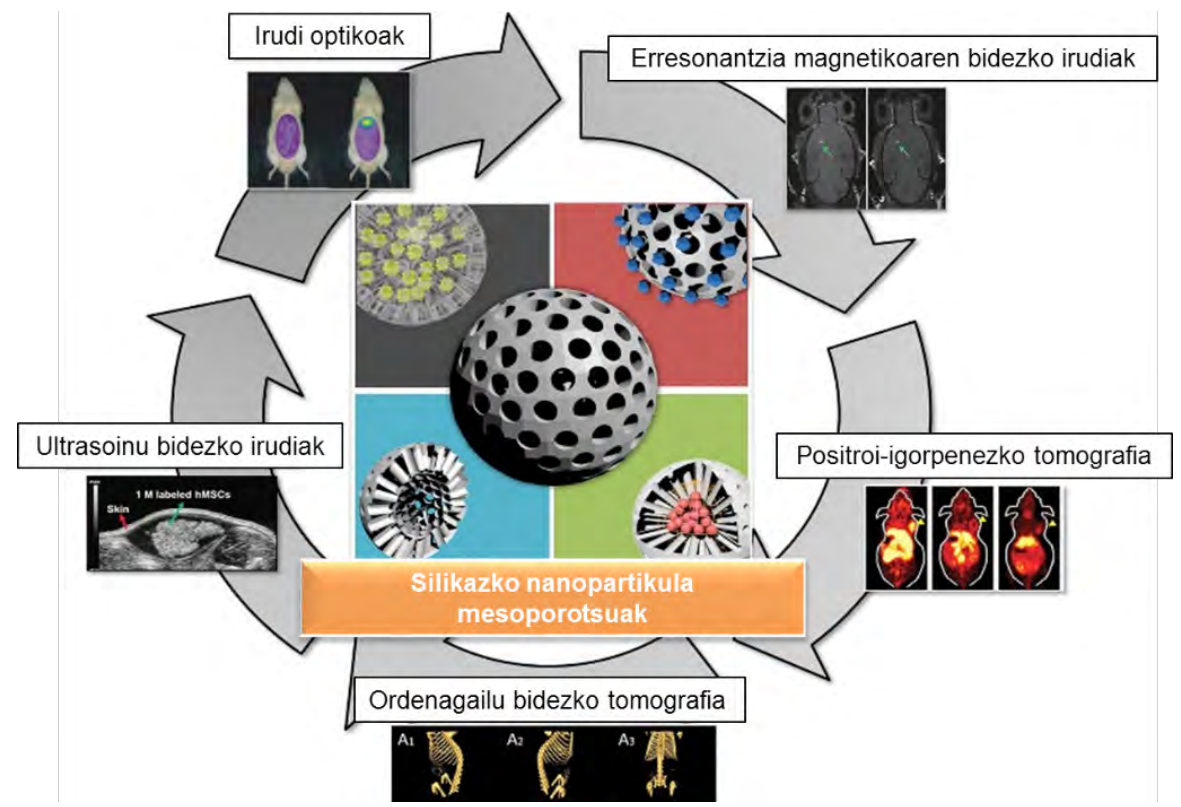

9. irudia. Hainbat aplikazioren ilustrazio eskematikoa silikazko nanopartikula mesoporotsuak erabiliz [23].

MSNen bioirudien arloko erabilera askotarikoa den arren, ondoren adibide bat aztertuko da, irudi optikoen arloan, hain zuzen ere. C.-S. Yang-ek eta L.-W. Lo-k Adv. Funct. Mater aldizkarian 2009. urtean argitaratutako artikuluan, MSNetan oinarritutako infragorri hurbilerako zunda bat garatu zuten. Hasteko, indiozianina berdea (ICG) (ikus 10. irudia) erabili zuten. Konposatu hau kontraste-agente bat da, eta eszitazio fluoreszenteko $(800 \mathrm{~nm})$ eta emisioko $(820 \mathrm{~nm})$ uhin-luzeren ezaugarriak dituzten aplikazio klinikoetarako erabilgarria da [24]. 


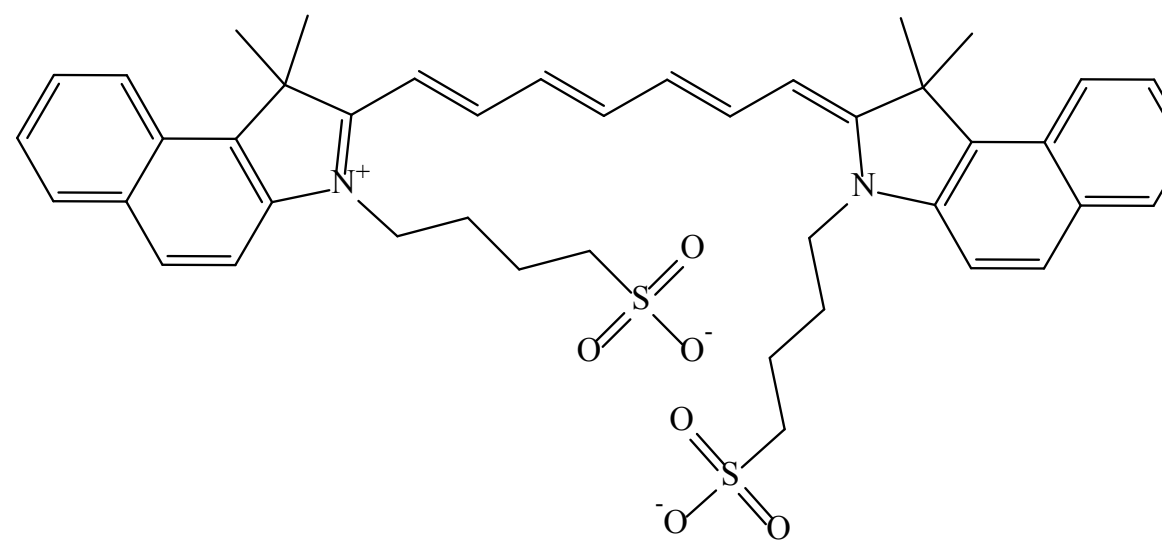

10. irudia. Indiozianina berdea kontraste-agentearen egitura kimikoa.

Indiozianina berdea MSNetan kapsulatzeko asmoz, nanopartikulak trimetilamonio taldeekin funtzionalizatu zituzten kontraste-agentea elkarrekintza elektrostatikoen bitartez adsorbatzeko. Adsorbitu ostean, pH probak egin zituzten, eta ohartu ziren konposatuak egonkorrak zirela $\mathrm{pH}$ fisiologikotik azidoetara. Gainera, fluoreszentzia probak egiterakoan, MSN bidezko ICG molekulen kapsularatzeak (MSN-ICG) fluoreszentzia-fotoien zenbaketa askoz ere altuagoak erakutsi zituen, kontzentrazio desberdinetarako ICG soluzioekin alderatuta (11. irudia) [24].

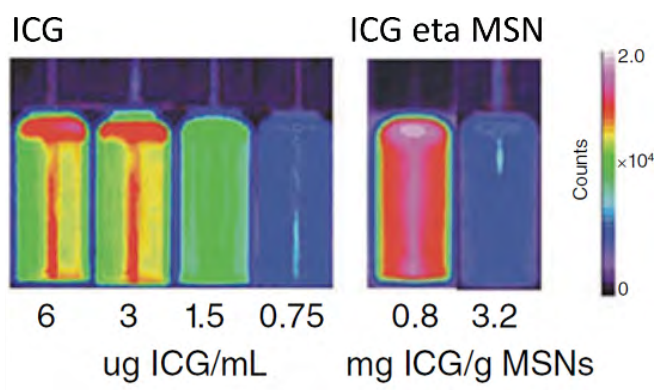

11. irudia. Ur-disoluzioetan ICG eta MSNICG kontzentrazio desberdineko irudi fluoreszentearen intentsitateak. 
Ondorioz, egonkortasun eta fluoreszentzia-intentsitate handiko kontraste-agente bat MSN bidezko nanoenkapsulatze-prozesuaren bidez diseina daiteke. Gainera, MSNek ICG molekulak degradaziotik babesten dituzte. Zunda optiko horren biobanaketa arratoi eta sagu ereduetan ebaluatu zen zain barneko injekzioaren ondoren. Horrek, MSNak, berehala, gibelean metatzen zirela erakutsi zuen, giltzurrunak, birikak, barea eta bihotza atzetik zituela. Beraz, emaitza horiek adierazten dutenez, MSNek, koloratzaile fluoreszenteak daramatzatenez, koloratzaile libreak baino fotoegonkortasun hobea berma lezakete [24].

Bestalde, orokortasunera itzuliz, MSNetan oinarritutako irudi-agenteak egiteko hainbat teknika zein konposatu mota erabiltzen dira [23, 25]. Hurrengo ataletan, erabiltzen diren konposatu mota batzuk azalduko ditugu.

\subsubsection{Koloratzaile organikoen eta MSNen arteko bateratzea}

Ikerlan askotan, koloratzaile organikoen eta MSNen arteko elkartze kobalentea MSNei irudi-agente erabilera emateko aukera kimiko sinpleetzat jaso da. Koloratzaile organikoa nanopartikulen gainazalean edo silize-matrizean elkartu daiteke. Lehenengo kasuan, gainazaleko silanol-taldeen aldaketa kimikoa erabil daiteke koloratzailearekin lotura kobalentea sortzeko. Hala nola, aminadun MSNa sintetiza daiteke, koloratzaile organikoarekiko lotura eman dezan. Bigarren kasuan, berriz, koloratzaile organikoa silanozko agente egoki batekin erreakzionarazten da, koloratzaile organiko-silanozko agente konplexu bat eratzeko. Ondoren, MSNak sintetizatzen dira koloratzailearen konplexua eta ohiko silika-iturria erabiliz (gehienetan TEOSa). Honela, koloratzailea nanopartikularen matrizean geratzen da [23, 25].

\subsubsection{Puntu kuantikoa (quantum dot, $Q D$ )}

Quantum dot-ak erdieroaleak diren egitura nanometrikoak dira, eta koloratzaile organikoekin alderatuz, zenbait abantaila dituzte. Adibidez, QDren emisioa molda daiteke ikuskorraren eta infragorriaren artean, QDen propietate fisiko-kimikoak kontrolatuz. Bestalde, beste propietate batzuek, hala nola fotoegonkortasun zein absortzio koefiziente altuek, kontraste optikoko agente bikainak izatea ahalbidetzen dute. Dena den, QD metal astunek eragindako toxikotasunak irudi-agente gisa erabiltzea eragozten du. Toxikotasun hori saihesteko, QDan kapsulatzea aukera egokia izan daiteke; horretarako, QDa silikazko geruza mesoporotsu mehe batekin estaltzen da [23, 25-26].

\subsubsection{Upconverting nanopartikulak}

Upconverting nanopartikulak energia baxuko bi fotoi edo gehiago absorbatu eta energia handiagoko fotoi batean eraldatzeko gai diren partikula nanometrikoak dira. Oro har, absortzioa infragorrian gertatzen da, eta emi- 
sioa, aldiz, ultramore edo ikuskorrean. Hori dela eta, aurretik aipatutako konposatuekin alderatuz, nanopartikula hauek zenbait abantaila dituzte. Hala nola, ehunarentzat ez da kaltegarria, ehunak oro har gardenak baitira infragorri argiaren pean. Nanopartikula hauek, lantanidoez edo aktinidoez dopatutako trantsizio-metalak izan ohi dira. Normalean, nanopartikula hauek MSNen barruan kapsulatzen dira [23, 25-26].

\section{ETORKIZUNARI BEGIRA}

1990eko hamarkadatik gaur egun arte, nanopartikula hauek izan ditzaketen erabilera askotarikoak ikertu dira, eta biomedikuntzaren arloan bereziki interes handikoak dira. Hala eta guztiz ere, in vivo probak egin diren arren, ez dira gizakietan probatu. Hori dela eta, zaila da iragartzea etorkizunean konposatu hauek gaur egun dauden produktuak ordezkatzeko gai izango ote diren. Dena den, MSNak moldakortasun handiko konposatuak eta optikoki gardenak direnez, etorkizun oparoko konposatuak izan daitezke. Orain arte gehien ikertutako arloa drug delivery izeneako izan da; izan ere, farmakoak garraiatzeko ohiko nanoportadoreak dituzten mugak (hala nola, etekin baxua, produkzio-koste altua, farmakoaren karga-ahalmen eskasa...) gainditzen dituzte. Edonola ere, etorkizunari begira, zenbait galdera daude oraindik erantzunik gabe, eta etorkizuneko ikerketen ardatz izan beharko dute. Hala nola, zeintzuk izango dira partikulen ezaugarri idealak (tamaina, morfologia, farmakoa kargatzeko estrategia, eta abar) erabilera klinikorako? Sendagaiak garraiatzeko zein izango da mekanismo egokiena?... Hala ere, seguru gaude datozen urteetan hainbat aurrerapauso eman ahal izango dira.

\section{ESKER ONAK}

Eskerrak eman behar dizkiot Eusko Jaurlaritzari ikertzaile ez-doktoreen prestakuntzarako doktoratu aurreko laguntza emateagatik.

\section{BIBLIOGRAFIA}

[1] JONAS G. CROISSANT eta C. JEFFREY BRINKER. 2018. «Biodegradable Silica-Based Nanoparticles: Dissolution Kinetics and Selective Bond Cleavage». The Enzymes, 43, 181-214.

[2] ROY M. HARRISON. 2007. Principles of Environmental Chemistry. The Royal Society of Chemistry, Erresuma Batua.

[3] R. JUGDAOHSINGH. 2007. «Silicon and bone health». J. Nutr Health Aging. 11, 99-110. 
[4] RIMPEI KAMEGAWA, MITSURU NAITO eta KANJIRO MIYATA. 2018. «Functionalization of silica nanoparticles for nucleic acid delivery». Nano Research. 11, 5219-5239.

[5] ADAYA GALLARDO, JAVIER O. MORALES, JÚLIA COMAS-BARCELÓ, THIBAULT GALLAVARDIN, PILAR ACEDO, ÁNGELES VILLANUEVA eta SANTI NONELL. 2015. «20 - Silica-based nanostructured materials for biomedical applications». Applications of Nanoscience in Photomedicine, 429-448.

[6] JONAS G. CROISSANT, YEVHEN FATIEIEV eta NIVEEN M. KHASHAB. 2017. «Degradability and Clearance of Silicon, Organosilica, Silsesquioxane, Silica Mixed Oxide, and Mesoporous Silica Nanoparticles». Adv. Mat., 29, 1604634-1604685.

[7] MIGUEL MANZANO eta MARÍA VALLET-REGÍ. 2019. «Mesoporous Silica Nanoparticles for Drug Delivery». Adv. Funct. Mater., 30, 19026341902634.

[8] REEMA NARAYAN, USHA Y. NAYAK, ASHOK M. RAICHUR eta SANJAY GARG. 2018. «Mesoporous Silica Nanoparticles: A Comprehensive Review on Synthesis and Recent Advances». Pharmaceutics, 10, 118167.

[9] WERNER STÖBER, ARTHUR FINK eta ERNST BOHN. 1968. «Controlled growth of monodisperse silica spheres in the micron size range». Journal of Colloid and Interface Science, 26, 65-69.

[10] XIAO-DONG WANG, ZHENG-XIANG SHEN, TIAN SANG, XIN-BIN CHENG, MING-FANG LI, LING-YAN CHEN eta ZHAN-SHAN WANG. 2010. «Preparation of spherical silica particles by Stöber process with high concentration of tetra-ethyl-orthosilicate». Journal of Colloid and Interface Science, 341, 23-29.

[11] ALEXANDER LIBERMANA, NATALIE MENDEZA, WILLIAM C. TROGLER eta ANDREW C. KUMMEL. 2014. «Synthesis and surface functionalization of silica nanoparticles for nanomedicine». Surface Science Reports, 69, 132-158.

[12] ANNA WATERMANN eta JUERGEN BRIEGER. 2017. «Mesoporous Silica Nanoparticles as Drug Delivery Vehicles in Cancer». Nanomaterials, 7 , 189-206.

[13] IGOR I. SLOWING, JUAN L. VIVERO-ESCOTO, BRIAN G. TREWYN eta VICTOR S.-Y. LIN. 2010. «Mesoporous silica nanoparticles: structural design and applications». J. Mater. Chem. . 20, 7924-7937.

[14] DONGYUAN ZHAO, JIANGLIN FENG, QISHENG HUO, NICHOLAS MELOSH, GLENN H. FREDRICKSON, BRADLEY F. CHMELKA eta GALEN D. STUCKY. 1998. «Triblock Copolymer Syntheses of Mesoporous Silica with Periodic 50 to 300 Angstrom Pores». Science. 279, 548-552.

[15] SAM M. EGGER, KATIE R. HURLEY, ASHISH DATT, GARRETT SWINDLEHURST eta CHRISTY L. HAYNES. 2015. «Ultraporous Mesostructured Silica Nanoparticles». Chem. Mater. 9, 3193-3196. 
[16] TEWODROS ASEFA eta ZHIMIN TAO. 2012. «Biocompatibility of Mesoporous Silica Nanoparticles». Chem. Res. Toxicol., 11, 2265-2284.

[17] M. VALLET-REGI, A RÁMILA, R. P. DEL REA eta J. PÉREZ-PARIENTE. 2001. «A New Property of MCM-41: Drug Delivery System». Chem. Mater., 13, 308-311.

[18] FANGQIONG TANG, LINLIN LI eta DONG CHEN. 2012. «Mesoporous Silica Nanoparticles: Synthesis, Biocompatibility and Drug Delivery». Adv. Mat., 24, 1504-1534.

[19] JESSICA M. ROSENHOLM, CECILIA SAHLGREN eta MIKA LINDEN. 2012. «Multifunctional Mesoporous Silica Nanoparticles for Combined Therapeutic, Diagnostic and Targeted Action in Cancer Treatment». Curr. Drug. Targets, 12, 1166-1186.

[20] HONG YAN, CATHLEEN TEH, SIVARAMAPANICKER SREEJITH, LIANGLIANG ZHU, ANNA KWOK, WEIQIN FANG, XING MA, KIM TRUC NGUYEN, VLADIMIR KORZH eta YANLI ZHAO. 2012. «Functional Mesoporous Silica Nanoparticles for Photothermal-Controlled Drug Delivery In Vivo». Angew. Chem. Int. Ed., 51, 8373-8377.

[21] H. M. DHAMMIKA BANDARA eta SHAWN C. BURDETTE. 2012. «Photoisomerization in different classes of azobenzene». Chem. Soc. Rev., 41, 1809-1825.

[22] YIN-JIA CHENG, GUO-FENG LUO, JING-YI ZHU, XIAO-DING XU, XUAN ZENG, DONG-BING CHENG, YOU-MEI LI, YAN WU, XIANZHENG ZHANG, REN-XI ZHUO eta FENG HE. 2015. «Enzyme-Induced and Tumor-Targeted Drug Delivery System Based on Multifunctional Mesoporous Silica Nanoparticles». ACS Appl. Mater. Interfaces, 7, 9078-9087.

[23] BONG GEUN CHA eta JAEYUN KIM. 2019. «Functional mesoporous silica nanoparticles for bio-imaging applications». WIREs Nanomed Nanobiotechnol. 11, 1515-1537.

[24] CHIA-HUNG LEE, SHIH-HSUN CHENG, YU-JING WANG, YU-CHING CHEN, NAI-TZU CHEN, JEFFREY SOURIS, CHIN-TU CHEN, CHUNGYUAN MOU, CHUNG-SHI YANG eta LEU-WEI LO. 2009. «Near-Infrared Mesoporous Silica Nanoparticles for Optical Imaging: Characterization and In Vivo Biodistribution». Adv. Funct. Mater. 19, 215-222.

[25] FEBY WIJAYA PRATIWI, CHIUNG WEN KUO, SI-HAN WU, YI-PING CHEN, CHUNG YUAN MOU eta PEILIN CHEN. 2018. «The Bioimaging Applications of Mesoporous Silica Nanoparticles» The Enzymes, 43, 123153.

[26] SAMIRA JAFARI, HOSSEIN DERAKHSHANKHAH, LOGHMAN ALAEI, ALI FATTAHI, BEHRANG SHIRI VARNAMKHASTI eta ALI AKBAR SABOURY. 2019. «Mesoporous silica nanoparticles for therapeutic/diagnostic applications». Biomedicine \& Pharmacotherapy,109, 1100-1111. 